\title{
Educación Integral en el huracán contemporáneo"
}

\author{
David Andrés Jiménez ${ }^{* *}$
}

Recibido: 11 de octubre de 2016 • Aprobado: 01 de noviembre de 2016

\section{Resumen:}

Artículo que retoma resultados investigativos en el área de la Educación Integral en la Maestría en Educación de la Universidad Santo Tomás. Para realizarlo empieza por una lectura del contexto sociopolítico al que se enfrenta la propuesta investigativa de carácter descriptivo-documental. La investigación de orden cualitativo usa la recurrencia en posturas y en contenidos de los textos para identificar, mediante el análisis del discurso, tres posibles perspectivas ordenadoras de la formación integral en la educación superior. Por último, expone elementos sustantivos en la reflexión pedagógica en pos de una formación integral que transforme los horizontes políticos, sociales y culturales hasta hoy hegemónicos.

Palabras claves: Educación Integral, Sociedad, Educación Crítica, Política, Subjetividad.

Producto de la investigación Formación Integral en la Maestría de Educación de la Universidad Santo Tomás coordinada por el autor del documento y adscrita a la Línea "Educación, Derechos Humanos y Ciudadanía" de la VUAD en la Universidad Santo Tomás llevada a cabo en el segundo semestre de 2013 y todo el año 2014. Pesquisa asignada mediante plan de trabajo en donde se solicitó la actualización de un módulo formativo para apoyar los seminarios de la temática en el programa.

Antropólogo de la Universidad Nacional de Colombia, Magister en Desarrollo Educativo y Social de la Universidad Pedagógica Nacional-Colombia, Doctorando en Estudios Sociales de América Latina en la Universidad Nacional de Córdoba-Argentina. Actualmente es Docente de tiempo completo de la Maestría en Educación de la Vicerrectoría de Educación Abierta y a Distancia -VUAD- de la Universidad Santo Tomás-Colombia. Correo: davidjimenez@ ustadistancia.edu.co; dirección postal Carrera 9A No. 63 - 28, Bogotá-Colombia. 


\title{
Integral Education in the contemporary hurricane
}

\begin{abstract}
Abstrac:
The article show research results about the Integral Education in the Masters in Education at the University Of Santo Tomas Colombia. It made a tour by the sociopolitical context and it shows how the documental research proposal can identify three perspectives that help in comprehend this issue today in the high education. The research, registered in the qualitative paradigm, uses recurrence in topics to organize the documents after a discourse analysis. Finally, the article speaks about substantive issues in the pedagogic analysis to generate a integral education that can change the hegemonic political, social and cultural horizons.
\end{abstract}

Keywords: Integral Education, Society, Critical education, Policy, Subjectivity.

\section{Éducation intégrale dans l'ouragan contemporain}

\section{Résumé}

Cet article reprend les résultats des recherches dans le domaine de l'éducation intégrale dans le Master en Éducation de l'Université Santo Tomás (Saint Thomas). Pour le réaliser il commence par une lecture du contexte sociopolitique auquel fait face la proposition de la recherche de caractère descriptive-documentaire. La recherche d'ordre qualitative utilise la récurrence dans les points de vus et dans les contenus des textes pour identifier, à travers l'analyse du discours, trois possibles perspectives qui ordonnent la formation intégrale dans l'éducation supérieure. Finalement, il expose les éléments de fond dans la réflexion pédagogique à la recherche d'une formation intégrale qui transforme les horizons politiques, sociaux et culturels hégémoniques jusqu'à aujourd'hui.

Mots-clés: Éducation complète, Société, Éducation Critique; Politique, Subjectivité.

\section{Introducción}

La Educación integral o formación integral no puede ser un apéndice en ninguna institución, la Maestría en Educación de la Universidad Santo Tomás ha generado múltiples reflexiones sobre la temática y continuar este análisis será uno de sus objetivos. El presente documento resume la investigación "Formación Integral en la Maestría de Educación de la Universidad Santo Tomás" planteada al 
interior del programa y desarrollada en el periodo 2013-2014 con el objetivo de ver tendencias, recurrencias y perspectivas, mediante una revisión documental en la temática.

El artículo, dividido en cuatro apartados, empieza por ubicar el contexto social, político y cultural necesario para perfilar tanto el problema como los objetivos de la pesquisa. Posteriormente, reflexiona de manera sucinta sobre los elementos metodológicos más importantes; para pasar luego a los resultados organizados en las perspectivas identificadas y las apuestas más relevantes que las atraviesan. El último apartado, de manera exploratoria, piensa algunos elementos sustantivos en la reflexión pedagógica sobre una educación integral transformadora de las apuestas hegemónicas en la educación humana actual.

\section{Los Huracanes Socioeconómicos y Político-Culturales}

Los complejos contextos que se enfrentan en la actualidad imponen buscar explicaciones sobre los hechos en esta era globalizada. Roland Robertson plantea la necesidad de comprender la globalización actual en relación con las tensiones locales ${ }^{1}$ que genera; Antonio Bolívar utiliza esta postura y propone el término glocalización desde una perspectiva cultural en miras de pensar una realidad que mezcla tanto elementos locales como aspectos mundializados (2001, p. 269); Boaventura de Sousa Santos en su texto De la Mano de Alicia (1998) aborda cómo las tenciones contemporáneas generadas por las contradicciones de la modernidad ${ }^{2}$, proporcionan otra lectura de los desafíos que se tienen en la interpretación de las sociedades contemporáneas. La velocidad de la transformación social obliga a reconocer que las teorías, los conceptos, los modelos y las soluciones antes plausibles hoy se muestran insuficientes. Sin duda la modernidad y sus paradigmas contradictorios, al promover tanto la emancipación social como la regulación social, llevan a un estadio donde cumplir lo prometido es imposible. Es por esta

1 Su texto Globalization: social Theory and Global Culture (1992) es diciente al respecto. Otras posturas que abordan el tema son factibles de encontrar en Immanuel Wallerstein, Fredric Jameson y Ulrich Beck.

2 Para bordar más el tema de la modernidad y sus problemas podemos remitirnos a algunos autores (Apple, 2001; Bauman, 2000; Boustros-Ghali, 2003; Chomsky, 2004; León \& Zemelman, 1997; Gutmann, 2008; Nussbaum, 2010; Santos, 1998) los cuales han remarcado que el proyecto de la modernidad en el mundo actual está en crisis y que la postmodernidad lo vive cuestionando; en especial en conceptos como el de universalidad ya que los particularismos han demandado su inclusión en el debate. 
razón que las instituciones modernas (tribunales, universidades, escuelas, cárceles, hospitales, etc.) están constantemente en crisis. Ante ello Santos (2009) plantea la necesidad de pensar de otra manera ${ }^{3} \mathrm{y}$, así, no reproducir lógicas modernas que aumentan nuestra sensación de estar como Alicia cayendo por el túnel hacia el país de las maravillas.

Este torbellino social económico y cultural lo retrató Zygmunt Bauman de manera magistral en su texto Sobre la educación en un mundo líquido (2013); allí desarrolla elementos sustanciales del contexto y su relación con la educación actual. Plantea que el contexto determina tanto la calidad como la posibilidad y la utilidad de la formación humana. Nos da como ejemplo la disputa entre mixofilia y mixofobia ${ }^{4}$ fenómeno que en Europa ha permitido el surgimiento de políticas excluyentes basadas en el miedo al otro. También señala que enseñar en y para la revolución permanente algunas veces instaura aptitudes para "desmembrar y volver a organizar el marco cognitivo predominante, o bien desecharlo por completo sin sustituirlo por un elemento de reemplazo [...] [el remplazo hoy se ha convertido en una norma] en el proceso de enseñanza y aprendizaje" (Bauman, 2013, pp. 21-22). Aspecto cardinal en la medida que el principio de cambio se ha vuelto una cárcel y quien no esté acorde o se rezague en este huracán de cambios pasa a engrosar la inmensa cantidad de parias que el sistema genera (Bauman, 2005). El juego es macabro y violento. Los medios masivos de comunicación infunden miedo y justifican normas represivas bajo el supuesto interés de resolver conflictos socioeconómicos y político-culturales pero terminan por generar más miedo ${ }^{5}$ e instaurar mayores medidas de control. El problema de ello deviene posteriormente, ya que es muy difícil superar las elaboraciones socioculturales en donde la violencia, la explotación y la inhumanidad ha sido instaurada.

3 La necesidad de transformación del paradigma vigente es visible tanto en las ciencias naturales como en las sociales y es visible en "un movimiento de vocación tras-disciplinar que Jantsch designa como paradigma de la auto-organización que aflora en teorías como la teoría de Prigogine, en la sinergética de Haken, en el concepto de hiperciclo y en la teoría del origen de la vida de Eigen, en el concepto de atopoiesis de Maturana y Varela, en la teoría de las catástrofes de Thom, en la teoría de la evolución de Jantschm, y en la teoría del 'orden implicado' de David Bohm" (Santos, 2009, p. 35) para mencionar las apuestas en la misma ciencia llamada "positiva".

4 La mixofilia la podemos entender como el aprecio por la unión con la diferencia y la mixofobia como el miedo a mezclarnos con aquel que es diferente. Esta disputa se ha hecho más evidente en Europa ante la migración de extranjeros de países "subdesarrollados".

5 No podemos obviar el apoyo grandes poblaciones como las de Estados Unidos a las intervenciones violentas en diversos órdenes y niveles ejemplo de ello es Irak, Afganistán, Libia, Filipinas, etc. 
[...] La persona acostumbrada a ser despreciada y que pretende haberlo olvidado, ahora hará lo mismo con otros [ya que son] «cadenas esquismogénicas», auténticos nudos gordianos y robustos que se resisten a ser desatados o cortados [...]. El resultado de todo ello es el surgimiento de una mentalidad de «fortaleza asediada», que se manifiesta en la creciente y rápida popularidad de la que gozan las fronteras blindadas y las puertas firmemente atrancadas. (Bauman, 2013, pp. 16-17).

Colombia no ha estado ajeno a esta lógica tanto interna como externamente. $\mathrm{Al}$ interior con la regularización de la guerra y de manera externa ha apoyado la mayoría de las intervenciones de Estados Unidos en otras latitudes. Se ve con buenos ojos los pertrechos militares que envían para avivar diferentes tipos de conflictos. Incluso socioculturalmente se ha integrado este discurso al punto de que en los últimos comicios presidenciales (2014) la mitad del electorado aún cree en el uso de la guerra como estrategia válida para resolver el conflicto. Táctica que lleva más de medio siglo de aplicación y con pocos resultados.

Se sigue reproduciendo el esquema hegemónico como lo plantea Chomsky (2004) o de imperialismo como lo concibe Hard y Negri (2002); modelo acompañado por una tiranía y opresión del mercado que Thomas Hylland Eriksen en su texto Tyranny of the Moment [La tiranía del momento] (2001) ha descrito de manera soberbia: el proceso que el mercado hace con nosotros podemos catalogarlo como un aturdimiento mediante la puesta en escena de infinidad de información al punto de confundir a quien la recibe, de esta manera evita que reaccione. Como hay tantos datos quedamos sin distinguir entre lo importante y lo irrelevante. La información no deseada, se convierte en un ruido que desarticula no solo las narrativas sino la noción de realidad y hace que únicamente se vea una pequeña parte de la totalidad; impide ver el contexto en el cual se encuentra. La selección en este bullicio permite dos dinámicas fundamentales: a) un sistema de producción de nuevos objetos de deseo que cambian frecuentemente gracias a lo conocido como la obsolescencia controlada ${ }^{6} ; \mathrm{y}$ b) una forma hábil para ocultar las consecuencias generadas por un sistema que al ubicar la novedad como deseo básico genera una gran cantidad de desperdicios. Este mundo huracanado, líquido diría Bauman, alimentado por dinámicas y valores económicos que ordenan tanto lo político

6 Podemos entenderla como aquel diseño del fin de la vida útil tanto de un producto como de un servicio. La idea se remonta a principios del siglo XX con el Crash del 30 y la idea de animar el consumo mediante este sistema que programa un tiempo de vida útil y posteriormente tanto el servicio como el producto se vuelve obsoleto, no funcional, inútil o inservible. 
como lo social y lo cultural desde su apuesta por lo individual que desprecia lo colectivo.

Colombia -con países como Chile, Perú y México- es abanderada de propuestas socioeconómicas afines a los tratados de libre comercio firmados en los últimos años en la región. Más allá de las promesas que auguran ganancias y mieles al por mayor, las cifras de importación y exportación muestran la enorme desventaja de estos tratados. Nuestros sistemas de producción, distribución y formación tanto científica como tecnológica están muy por debajo de niveles óptimos para competir con países como Estados Unidos y Corea del Sur, por mencionar solo dos casos. La matriz histórica permitió que Colombia tuviera un híper-desarrollo de sectores como el bancario y de servicios en detrimento de otros (empresas textiles, marroquinería, etc.). Asistimos a un impulso gubernamental de una industria de extracción que sigue desregulada ${ }^{7}$ a la par que su desarrollo y regulación es casi inexistente; a lo cual se suma la guerra constante que impide propuestas alternativas de desarrollo.

En este contexto vemos cómo nuestro sistema educativo impulsa principios de mercado (competencia, excelencia, eficacia, eficiencia, etc.), los cuales, por más que tengan múltiples acepciones, son interpretados en un sentido más economicista y lucrativo. Esto es visible en la implementación acrítica de las competencias con la clasificación de estudiantes entre competentes e incompetentes; se ve cómo el discurso de la eficacia y eficiencia sustenta una matriz cultural donde lo privado es bueno y lo público es malo. Lo cual es apoyado al adoptar estrategias de mercado que no solo privilegian inversiones privadas, sino que instauran dispositivos de endeudamiento (léase regulación) de quienes se forman en la educación superior. En los últimos años esto ha llevado a que aparezcan movimientos sociales que reivindican otro tipo de educación ${ }^{8}$.

Si se reconoce que la riqueza de una nación está en el trabajo de su gente, vieja claridad económica, se debería comprender que la riqueza será mayor si se

7 Esto es visible en la cantidad de concesiones mineras y petroleras a grandes multinacionales, a la par que existen múltiples vacíos en el control de la minería ilegal que destruye el ambiente en los departamentos periféricos del país.

8 Es interesante revisar las consignas de los movimientos estudiantiles en Colombia que en cabeza de la MANE en los últimos años han mostrado la necesidad de unión entre estudiantes y universidades tanto públicas como privadas por una Ley de Educación que no acabe con la posibilidad de tener un país con personas bien formadas. Es por ello que han propuesto la mayor participación del Estado con un papel preponderante tanto en la financiación como en los principios que guían la educación, no solo en la evaluación; de esa manera dejarían de proliferar institutos de dudosa calidad que terminan siendo una inversión inocua y limitan el progreso del país. 
estuviera cualificado. El sistema educativo sigue jerarquizado y en este orden los sectores económicos se han aliado con los políticos para establecer intereses privados más que públicos. La mega-especialización ha generado distancias infranqueables en algunos procesos formativos vía hiper-valoración de procesos económicos e infra-valoración de la educación humanista. Es por ello que propuestas como las del profesor Wallerstein (1996) impulsan a la formación interdisciplinar en la educación superior. La pedagogía sigue este camino y las lecturas interdisciplinares permiten formar sujetos críticos en un contexto capturado por el cambio veloz y por la hiper-abundancia de información.

En este contexto hay que cuestionarse por el proceso formativo y por el papel de la Maestría en Educación en el mismo. Así surgieron preguntas como: ¿qué espacios de reflexión son necesarios para abordar esta complejidad en un posgrado?, ¿cómo propiciar en los estudiantes de maestría tal interdisciplinariedad?, ¿qué espacio discursivo propicia la investigación educativa en cuanto este marco social, político y cultural? Estos cuestionamientos ven la educación integral como un campo de disputa en el cual, las reflexiones pedagógicas, leen el contexto y pretenden establecer apuestas formativas de sujetos. Ante la hegemonía de reflexiones pedagógicas capitalistas, diversos autores (Bauman, 2013; Böhrm, 2005; Hoyos Vásquez, 1998; Höffe, 2007; Nussbaum, 2010; Sen, 2006; Stiglitz, 2012) han exigido que las políticas y los educadores formen desde primados más humanizantes y menos economicistas. Por ende, solicitan no dejar de lado reflexiones éticas y morales sobre el papel del ser humano en el ámbito social ${ }^{9}$. Identificar estas reflexiones permitió establecer un objetivo de saber en el orden descriptivo: "Identificar las discusiones y perspectivas sobre la formación integral de un programa de posgrado en educación a distancia con énfasis investigativo, en pro de impulsar procesos reflexivos que permitan el acompañamiento a los seminarios de Formación Integral de la Maestría en Educación de la Vicerrectoría de Educación Abierta y a Distancia de la Universidad Santo Tomás"10.

9 En esta perspectiva los requerimientos del contexto no son olvidados, pero para no ser inmediatistas ubican las demandas en perspectivas diacrónicas que deben orientar la reflexión y acción de los educadores. Entre estas propuestas podríamos ubicar lo que Hemma León y Hugo Zemelman (1997) definen como historicidad; concepto que integra la visión del pasado, el presente y el futuro.

10 Los objetivos específicos pasaron por: a) identificar las discusiones y perspectivas en la Formación Integral que han alimentado la formación superior en otros programas y revisar su aporte a la Maestría en Educación de la Universidad Santo Tomás; y b) Caracterizar las discusiones que alimentan el campo de Formación Integral que deberían estar en un módulo sobre la temática en pos de las necesidades de acompañamiento reflexivo a los seminarios que en la Maestría en Educación de la Universidad Santo Tomás abordan la temática. Es de resaltar 


\section{Sobre el método}

El orden cualitativo de la pesquisa seleccionó la modalidad de investigación documental $^{11}$ y metodológicamente utilizó el análisis de discurso para identificar recurrencias en los textos, lo cual permitió identificar perspectivas al interior de la información rastreada. Los ámbitos de indagación fueron: algunos repositorios universitarios de la ciudad de Bogotá y las bibliotecas electrónicas Scielo y Redalyc; para responder a criterios de accesibilidad de los documentos al ser repositorios de libre acceso y al ser plataformas que contenían publicaciones arbitradas. Posteriormente a la selección e inventario en una base de datos con 106 registros, identificamos que 20 textos trabajaban de manera explícita la formación integral en relación con la educación superior; por ello nos dispusimos a identificar sus aportes a partir de revisar sus resúmenes e introducciones. Esta primera caracterización permitió identificar tres categorías que organizaban los documentos; y que posteriormente se convirtieron en las perspectivas ${ }^{12}$. La primera de las categorías organizadoras la componen los documentos cercanos al orden democrática, histórica y socio-crítica; se encontraron 55 registros relacionados con los temas de ciudadanía, democracia, convivencia, conflicto y paz. La segunda perspectiva, que aborda órdenes como el Técnico, el Tecnológico y el Científico y en ella se clasificaron 33 registros relacionados con temáticas como currículo, programas educativos, formación en tecnología, TIC, profesionalización y ciencia. Por último, en la tercera perspectiva se tipificaron 15 registros relacionados con conceptos como ética, valores, espiritualidad y humanismo; por lo que se decidió catalogar esta perspectiva como Ética, humanística y espiritualidad.

Posteriormente se identificó al interior de cada grupo documental, los documentos más relevantes que permitieran caracterizar las discusiones planteadas en cada perspectiva, con cuidado de no generar jerarquías. Los textos identificados,

que la investigación tuvo como producto central la elaboración de un módulo que apoyara los procesos de formación integral al interior de la Maestría y que se encuentra en prensa.

11 Tal como lo define la profesora Rosa María Cifuentes, a quien seguiremos en nuestro diseño investigativo, "el trabajo documental no es sólo una fuente o técnica de recolección de información. Se constituye en una estrategia de investigación con particularidades propias en el diseño del proyecto, la obtención de información, el análisis e interpretación" (Cifuentes, 2014, p. 77).

12 Es importante aclarar que entre muchos de los documentos abordan dos y hasta las tres perspectivas pero la construcción de las categorías obedeció a la necesidad de encontrar una forma de cumplir con los objetivos de identificar contenidos y caracterizar las discusiones en el campo de la Formación Integral. 
gracias a su posibilidad de descripción del campo de discusión fueron reseñados mediante un RAE en donde, gracias a un análisis de discurso, se hizo énfasis en la caracterización de las discusiones planteadas. Catorce (14) documentos alimentaron este análisis y clasificación de información, dos principios -recurrencia y saturación de la información- fueron fundamentales en este paso. A su vez, algunos de los artículos fueron leídos y discutidos en tres (3) seminarios de formación integral al interior de la Maestría de Educación ${ }^{13}$. Este ejercicio permitió comprender que: a) hay múltiples perspectivas sobre la formación integral y no se pueden reducir simplistamente; b) hay un énfasis en temas de Derechos Humanos, Democracia y Ciudadanía, se incluyen también aspectos teóricos y didácticos en muchos de los documentos; c) existen conceptos transversales como sociedad del conocimiento, multiculturalidad, ética, personalidad, globalización, liberalismo, desarrollo humano, Estado, empoderamiento, emancipación, individualización y reflexión crítica que alimentan la mayoría de los textos; d) muchos documentos analizan en diferentes niveles por lo que atraviesan diferentes países y contextos, por ello se comprende que las reflexiones expuestas están en una continua tensión entre visiones micro y macro; y f) el tema de los valores se convierte en un hilo conductor importante, porque aparece transversalmente en los tres agrupamientos o enfoques.

\section{Resultados, perspectivas y discusiones}

Para recorrer las perspectivas identificadas primero se desarrollará una definición básica del concepto y luego se revisarán las tres perspectivas encontradas para describir algunos rasgos sustantivos.

La Formación Integral implica hablar de los dos elementos del concepto. Gadamer en su texto Verdad y método postula que la formación es "el más grande pensamiento del siglo XIX" y, por ende, es uno de los pilares del humanismo moderno (Gadamer, 1990: 15; en Vargas, 2010, p. 147). La educación es parte de la configuración de la persona. En la baja edad media se planteaba la formación del ser humano como el desarrollo de la imagen de Dios en cada ser humano. Gracias a la Ilustración y el romanticismo esto cambia y el concepto se amplía

13 Un grupo en $3^{\circ}$ y $4^{\circ}$ semestre, y otro grupo en $2^{\circ}$ Semestre, en donde fueron trabajados los documentos, a los cuales se les realizó 40 reseñas y 10 reflexiones que giraron sobre la temática y sobre las estrategias didácticas en formación integral en la Maestría. Por lo que agradecemos la participación de los estudiantes quienes con sus reflexiones, trabajos y aportes enriquecieron el horizonte de trabajo. 
para llevarlo a ámbitos como el estético, el pedagógico y el político (Vargas, 2010, p. 148). Al atribuirle estas características se vuelve un proceso amplio de transformación de sí mismo que le permite a la persona alcanzar la madurez de sus capacidades espirituales y corporales.

Asimismo, la formación permite desenvolver una representación global de donde nos encontramos. El humanismo planteó que el trabajo permitía la autoconsciencia y el volverse hombre (Hegel, 1985). Se tiene en cuenta que el concepto 'trabajo' ha cambiado y la especialización, la tecnificación y la complejización de los oficios ha puesto al conocimiento como el eje de la formación. La educación hoy tiene que ver con intereses en el conocimiento para comprender y transformar el mundo ${ }^{14}$. Es tan fuerte el mismo que ha determinado la forma en que vemos el mundo, las relaciones de las personas, la teorización, la nominación y el control. La construcción de lo humano en la actualidad pasa por la creación, tenencia, relación e intercambio del conocimiento. Los anteriores intereses han construido un sistema educativo que ha crecido a la par y ha permitido transformar la noción de educación. En principio tenía que ver con los procesos de socialización en los que interviene un maestro o profesor y hay un estudiante o aprendiz que está entre la niñez y la juventud; hoy este proceso ha ampliado el rango y ha integrado a todas las etapas de la persona ya que ha ido hacia su posicionamiento en el mundo social y político (Vargas Guillén, 2007).

El concepto de integralidad al venir etimológicamente del latín integralis, la podemos entender como un adjetivo que habla "de cada una de las partes de un todo: Que entra en su composición sin serle esencial, de manera que el todo puede subsistir, aunque incompleto, sin ella" (Real Academia Española-RAE-), dándonos la posibilidad de hablar de educación integral como el proceso que forma en cada una de las partes de un todo. ¿Pero cuál es ese todo? La revisión documental permitió encontrar claridades sobre lo que esta integralidad puede significar hoy. En la actualidad lo "integral" está asociado con propuestas de diferentes áreas ordenados por postulados económicos y desarrollistas. Documentos de la Organización de los Estados Americanos -OEA- y la biblioteca virtual del Banco de la República (2014) hacen referencia al desarrollo integral como el proceso que busca una idea de desarrollo y perfeccionamiento humano. En una revisión aguda vemos cómo la

14 Tradición que tiene anclaje en el interés de apropiación del mundo y esgrime al menos cuatro elementos: 1) proceso de valentía para enfrentarse a lo extraño y dejarse confrontar; 2) la formación no tiene que ver con lo planeado se acerca una especie de aventura guiadas por el deseo de búsqueda; 3) es una forma de desinstalarse de lo familiar que relativiza las convicciones; y 4) tiene que ver con la transformación de la persona, de lo cotidiano de manera responsable y en relación con el mundo (Vargas, 2010, pp. 151-154). 
OEA menciona que esta apuesta está acompañada por políticas que buscan fomentar el desarrollo sostenible en los países subdesarrollados (OEA, 2014).

Se reconocieron tres grupos de definiciones sobre formación integral: unas muy psicológicas, otras religiosas y unas más gubernamentales e institucionales. Para las psicológicas "implica el desarrollo de todo el ser humano; los factores conativo-volitivo, epistémico-cognoscitivo, afectivo-emotivo, y, por último, hasta somático-físico, [por ello] son fundamentales en la elaboración de los curricula (Sic) en todo los niveles del proceso educativo" (Picardo, 2004). Las religiosas relacionan la formación integral con el reconocimiento de la presencia de un ser supremo y el desarrollo de las cualidades que esta deidad ha generado en la persona. La normativa es contextual porque está basada en la Ley colombiana. En la Ley 115 de 1994 en su Artículo No. 5 el Estado define los fines de la educación y la define como “El pleno desarrollo de la personalidad sin más limitaciones que las que le imponen los derechos de los demás y el orden jurídico, dentro de un proceso de formación integral, física, psíquica, intelectual, moral, espiritual, social, afectiva, ética, cívica y demás valores humanos" (Congreso de la República, 1994). Lo cual está complementado cuando los Decretos sobre Evaluación (230 y 1290) y muchos de los comunicados del Ministerio de Educación Nacional (MEN, s. f) hacen énfasis en la educación en una sociedad del conocimiento y propone entender la formación integral tanto como un ejercicio y un compromiso institucional y colectivo por "alcanzar un fin ético en las personas, en virtud del cual reinventar, ante las adversidades de los tiempos, el valor de la existencia social, cultural, humana y ambiental" (MEN, s. f, p. 9). Por último, retomando la comprensión del profesor Julio Cesar Vargas sobre la formación integral en las instituciones de educación superior "hace alusión a la importancia de la formación estética, ciudadana y disciplinar" (Vargas, 2010, p. 161). La complejidad al hablar de educación integral es evidente. Las tres categorías ordenadoras generadas por la investigación permiten proponer un orden: La perspectiva técnica, tecnológica y científica; la ética, humanística y espiritual; y, por último, la democrática, histórica y socio-crítica son esquemas organizativos no excluyentes por lo que no los consideramos espacios separados y/o antagónicos. La investigación permitió ver que las categorías están yuxtapuestas, se mezclan, se entrelazan y se solapan entre ellas. Aunque se desarrollarán de manera separada solo buscamos una claridad conceptual sobre los énfasis formativos. 


\section{Perspectiva técnica, tecnológica y científica.}

Los conceptos de desarrollo se apegan mucho a esta perspectiva ya que los teóricos ven en la educación integral el camino para alcanzar índices de desarrollo equiparables a otros países. El contexto de avance técnico y tecnológico que se experimenta hoy supone que la formación permitirá generar riqueza. Discurso institucionalizado e impulsado por organismos internacionales, el cual ha tenido críticas de quienes han visto en él un mecanismo para que el mercado imponga una perspectiva formativa que desprecia algunas posturas humanistas y entroniza la perspectiva economicista (Bauman, 2013; Bolívar Botía, 2001; Eriksen, 2001; Höffe, 2007; Santos, 1998; Stiglitz, 2012; Martínez Boom, 2004).

Las instituciones educativas son declaradas como el lugar idóneo para la transformación social por ello su masificación pretende el fomento del "desarrollo sostenible y de la consecución de los objetivos internacionales de desarrollo mediante la investigación y el saber" (UNESCO, 2008, p. 23). Fenómeno ligado a la imposición de los conceptos de eficiencia y eficacia en los sistemas educativos. Martínez Boom muestra que este fenómeno convirtió al aparato escolar en la empresa de formación de sujetos competentes y competitivos en el mercado; el proceso se denomina como la "escuela competidora" (Martínez Boom, 2004).

La producción de sujetos consumistas ${ }^{15}$, conformistas, jerarquizados y competitivos está relacionado con concepciones radicales de lo moderno, lo económico y lo eficiente. Tedesco (1995, pp. 72-73) al hablar de la educación para el trabajo y para la ciudadanía en América Latina muestra cómo el discurso de la calidad, la productividad y la eficacia de la escuela, lo que genera un nicho bastante apacible para la educación competencia. Este discurso ha sido adaptado en la mayoría de las instituciones enlazado a la superación de la capacidad cognitiva en los exámenes internacionales ${ }^{16}$; para responder a los procesos de "selección" laboral que generan más desigualdad. Esta perspectiva establece que se tiene que garantizar la formación básica en: “a) Tecnologías de información, sistemas e internet, acceso a redes y sistemas de información. b) Dominio del inglés como

15 Competencia básica de la actual realidad.

16 "No hace falta mencionar la crítica de Foucault a las Ciencias Humanas en su obra 'Las palabras y las cosas', ni la crítica que hace Heidegger al humanismo moderno, para mostrar que la educación humanista está en crisis. En el actual período de globalización los conceptos de formación y educación humanista han caído en desuso, dando paso a una educación basada en 'competencias', o dirigida a garantizar la 'calidad' del proceso de enseñanza-aprendizaje" (Vargas, 2010, p. 157). 
lengua académica. c) Flexibilidad entendida como la capacidad de adaptación a la cambiante oferta laboral y al rápido avance de las tecnologías. d) Disposición para una capacitación permanente con resultados visibles a corto plazo" (Vargas, 2010, p. 161). Formar en estos ámbitos no es negativo, lo complicado es cuando estas perspectivas privilegian enfoques donde la competencia desmedida, el emprendimiento sin responsabilidad social, el éxito personal y no social, etc. ya que terminan entronando al ciudadano económico y consumidor sobre las demás perspectivas (Höffe, 2007).

\section{Perspectiva ética, humanística y espiritual.}

Los tres elementos integrados son muy amplios y demandarían atención específica; sin embargo, la lectura de los documentos permite entrecruzar estos elementos y muestra un recorrido que empieza por lo ético como reflexión sobre el buen vivir y los valores que esto conlleva; pasa por lo humanístico desde la necesidad de la opinión, la necesidad de adentrarse en la comprensión del lenguaje y de lo estético como algo sustancial para la formación de las personas; $\mathrm{y}$, por último, la perspectiva espiritual que reconoce múltiples paradigmas pero que tiene como centro la formación del espíritu humano como don de Dios.

Lo ético como reflexión de lo moral, la virtud, el deber, la felicidad y el buen vivir nos lleva a pensar el entramado de nuestro sistema de valores y cómo se desarrolla a nivel individual y social. En esta perspectiva "la formación del ser humano, si se quiere que sea integral, debe promover una manera de entender la vida humana y una orientación para su vida futura" (Ramos, 2004, p. 1). Por lo que estas perspectivas asumen que las reflexiones realizadas por el sujeto se proyectarán en actitudes concretas o en conductas consecuentes, ello define la forma en que nos relacionamos y, por lo tanto, la convivencia de la humanidad. Por lo cual esta perspectiva le apuesta a que la formación integral retome la dimensión ético-social.

Aquí se puede encontrar a Guillermo Hoyos Vásquez (1998), para quien es necesaria una ética para ciudadanos la cual "debería inspirarse en aquella tradición en la que se caracterizó el ethos precisamente en el contexto de la polis y debería además responder a quienes a nombre de una crítica a ciertos desarrollos de la modernidad" (Hoyos Vásquez, 1998, p. 2) que en últimas permitiría dar sentido a un encuentro comunicativo entre ciudadanos. Por ello, propone educar mediante actividades formativas a los ciudadanos y recuperar el tejido comunicativo en pos de un diálogo entre la comunidad y su identidad cultural; 
para recuperar el interés de las mayorías porque ellas permitirán generar un pluralismo razonable donde haya mínimos que permitan fortalecer la participación y enriquecer la convivencia (p. 13). Esta perspectiva se relaciona con el enfoque humanista que reconoce la humanidad en el uso de la doxa. Formar en la opinión lleva a la libertad del sujeto según la tradición Kantiana la cual demanda poner a consideración de otros su juicio crítico su posición. En esta perspectiva la educación integral demanda la retórica, el argumentar en público permitiría una mayoría de edad. Otra apuesta está en la formación en segundas lenguas bajo el principio de que la introducción al "mundo" se realiza mediante el lenguaje; por ende, si hay dominio de otras lenguas el sujeto podrá tener diferentes perspectivas de mundo posibles. Se puede encontrar en esta perspectiva la apuesta por la formación estética. Martha Nussbaum en su texto Sin fines de Lucro (2010) en el capítulo sexto: Cultivar la imaginación: la literatura y las artes, recuerda que el comprender al otro se hace en el juego para comprender cómo vive y siente el otro. Por eso, retoma posturas de Pestalozzi, Winnicott, Rouseau, Dewey y Tagore para indicar la importancia de la lúdica para la comprensión y que "la formación artística requiere de disciplina y ambición para ampliarse y extender las capacidades de comprensión y expresión" (Nussbaum, 2010, p. 144). Aspecto medular en apuestas por una formación en y para la democracia.

La perspectiva espiritual mostró análisis filosóficos rigurosos y aunque hay múltiples perspectivas se enunciará fundamentalmente la perspectiva tomista por ser del interés investigativo; sin dejar de recordar que la mayoría de propuestas hacen énfasis en la formación del espíritu humano como don de Dios. Las diferentes teorías religiosas plantean la existencia del ser humano como representación y soplo divino por ello es importante que él caiga en gracia de su dios y establezca como marco los principios propuestos por su religión.

Una reflexión tocante al aspecto espiritual del hombre nos dirige a establecer que es parte de la formación integral sin olvidarnos que este asunto tiene su enfoque en la dimensión religiosa de la persona humana. La visión cristiana respecto al hombre y del mundo nos permite aclarar grandes interrogantes que surgen en él sobre sí mismo, la sociedad o el mundo y la historia que el ser humano ha ido construyendo." (Ramos, 2004, p. 4)

El enfoque tomista plantea que todo hombre es persona al ser sustancial y completo. La racionalidad le da su individualidad y su libertad desde donde quiere el bien; para Santo Tomás la libertad es querer el bien. Cuando él desarrolla el bien mediante acciones valiosas es un individuo de valor y ello le da 
felicidad. Así mismo, la dignidad humana conferida por Dios con la idea de perfección lo ubica en el vértice de lo material y lo espiritual y le da las dimensiones: racional (Intelectual), espiritual (trascendencia) y moral (ética). Son estas mismas la que le permiten tener una relación entre Fe y Razón ya que ambas son otorgadas por Dios. El uso de estas dimensiones permite comprender que la "formación integral que permite al estudiante reconocerse a sí mismo como ser humano, con una tarea específica para realizarse como persona y crear unas relaciones más humanas y justas con el entorno natural y social" (VUAD-USTA, 2014).

\section{Perspectiva democrática, histórica y socio-crítica.}

Elementos como la ciudadanía, la democracia, los derechos humanos, el conflicto, la paz, además de la formación en/para los Derechos Humanos hacen parte del discurso de esta perspectiva. Entrecruzan posturas sobre la ética, la política, el poder, el empoderamiento y la emancipación con un énfasis en el contexto latinoamericano gracias a la reflexión sobre los conflictos a los que hemos asistido. El orden, tal como lo plantea el profesor Waldo Ansaldi (2012) se extiende en el tiempo $^{17}$ y van desde la colonia hasta el presente. La historia de América ha sido atravesada por el conflicto y sigue el molde europeo tanto por la colonización como porque seguimos en conflicto con ellos ${ }^{18}$. Nuestra pléyade de culturas no escapa a la dialéctica histórico-social porque las represiones vividas han pretendido aniquilar la diferencia y el pensamiento no ha podido escaparse a la noción de víctima ${ }^{19}$.

17 La perspectiva de Fernand Braudel retomada por Waldo Ansaldi no es larga su extensión en muchos años. "Alude a continuidades, permanencias, persistencias, recurrencias, a realidades que, en tanto elementos o factores esenciales, operan de modo relevante, decisivamente, sin rupturas radicales, a lo largo de los procesos históricos, de los cuales constituyen hilos conductores" (Ansaldi, 2012, p. 683).

18 Pensadores como Mariátegui, Silvio Frondizi, Alfredo Llanos, Ricaute Soles, Serrano Caldera, González Casanova, José Martí, Paulo Freire, Germán Arciniegas, Fals Borda y otros mostraron que el pensamiento latinoamericano ha girado en torno al pensamiento hegeliano dialéctico.

19 Los conflictos de distinto orden: cultural, económico, civil, políticos y militares han alimentado regímenes autoritarios y represores en lo cotidiano. Entre los más y significativos están: la dictadura e ignominia de Haití; las dictaduras instituciones de Cuba, Chile, Argentina y Brasil; las dictaduras híbridas de Guatemala y Paraguay; la influencia de Estados Unidos con su "política del buen vecino" que instauró la visión de "América para los americanos" y su intervención legal o ilegal contra de cualquier foco socialista o socialdemócrata en la región; las revoluciones fallidas de El Salvador, Colombia, Perú, Bolivia y demás guerrillas que fueron 
Las luchas populares que defienden la paz y el respeto por los derechos humanos en este continente han sido una constante aunque con matices, para depender de las configuraciones históricas particulares de cada región. La convivencia en América Latina ha estado signada por una violencia política de larga duración acompañada por una conflictividad militar constante aunque diferenciada. En el caso colombiano la misma genera entre el 15 y 20\% de las muertes violentas en nuestro país; violencia que sigue unida al dominio terrateniente que imposibilitó la consolidación de un Estado para mantener su poder oligárquico (Ansaldi, 2012, p. 375). No podemos dejar de lado periodos como La Violencia y el Frente Nacional con su política de seguridad nacional. “En términos de Pécaut, a La Violencia le sucedieron Las Violencias, pluralidad que, conforme Darío Betancourt Echeverry (1990: 58-60), resultó de particularidades regionales y una «compleja mezcla de aspectos políticos económicos, sociales, étnicos y culturales»" (Ansaldi, 2012, p. 380). Podemos mencionar: la violencia bipartidista, la económico-social, la delincuencial, la guerrillera, la narcotraficante y la paramilitar. Así los Derechos Humanos en Latinoamérica han estado ligados a la lucha por la construcción de un Estado y una ciudadanía en condiciones deplorables. A lo que hay que añadir los cuestionamientos a la utilidad de los Derechos Humanos en el contexto actual porque la soberanía del Estado, vía el mercado, está trasladada al Individuo y refuerza "la concepción contemporánea de derechos humanos que se caracteriza por la universalidad y la individualidad" (Sacavino, 2012, p. 45). Por ello las acciones individuales son las que terminan por interpelar a los Estados; a nivel interno o externo mediante organismos multilaterales de defensa de derechos humanos ${ }^{20}$.

En estas condiciones la formación en Derechos Humanos como proceso formativo integral ha tenido el papel de imprimir coherencia entre los principios y los sistemas creados para defenderlo. La educación en/para los Derechos Humanos se convierte en una recurrente mención en los documentos oficiales y una gran parte de autores la usan para sustentar la formación en ciudadanía, democracia y paz. En América Latina las primeras experiencias formativas en el tema

diezmadas o mantenidas en una espiral de violencia alimentada por "la continuidad de la dominación formalmente democrática" (Ansaldi, 2012, p. 487); más el narcotráfico el cual desde los 80 se ha extendido con su orden mafioso.

20 Entre los organismos más importantes está la Corte Interamericana de Derechos Humanos, la Comisión Interamericana de Derechos Humanos, los organismos del sistema interamericano de protección de derechos humanos que están adscritos a la OEA en 1959. También existe la Convención Europea de Derechos Humanos (1950) y La Carta Africana de Derechos Humanos y de los Pueblos (1981), cada una con organismos multilaterales que permiten la defensa de los derechos en cada país. 
se remiten a la década de los $80^{21}$ y su desarrollo siempre ha estado "en confrontación con un contexto político, económico, social y cultural que, por una parte, la desafía; por otra, la condiciona y, a veces, también la limita" (p. 69).

Los principios de la formación en/para los Derechos Humanos están dados por el Programa Mundial para la Educación en Derechos Humanos proclamado por la ONU. En el mismo se reconoce que esta educación contribuye en el ejercicio de los Derechos Humanos y es por ello que es fomentada. Y en el punto tres (3) plantea que: "es el conjunto de actividades que se realiza para la capacitación y la difusión de la información con el fin de crear una cultura universal de la esfera de los derechos humanos, mediante la transmisión de conocimiento, de la enseñanza de técnicas y mediante la formación de actitudes". Desde allí los países han integrado esta educación a su sistema educativo mediante políticas públicas.

A la par hay textos como: Ética, política y ciudadanía (Vasco, Et. al., 2009) el cual muestra la apuesta por la formación de sujetos críticos desde reflexiones en dos ámbitos: el ético-moral y el político-ciudadano. El texto Ciudadanos en son de paz: propuestas de acción no violenta para Colombia (López, Et al., 2008) hace un recorrido por diferentes aportes y reflexiones sobre lo que implica la no-violencia y el empoderamiento de las comunidades para que las propuestas de organización que han hecho las comunidades de paz estén en el marco de análisis. Los mismos son ejemplo del énfasis por formar ciudadanos críticos. Apuesta cercana a formación para la democracia escolar en donde hay investigaciones que discuten sobre las experiencias educativas democráticas. Bambozzi y otros (2013) muestran la necesidad de tener en cuenta las acciones de impacto a nivel micro y macro institucional para realizar posteriores reflexiones. No se puede dejar de lado los desarrollos de Freire (2005; 2007), o de Michael Apple (2001), Henry Giroux (2006), entre otros. Es precisamente Giroux quien conmina a pensar las instituciones como

lugares que ofrezcan la oportunidad de reuniones educadas; es decir, que les ofrezcan a los alumnos oportunidades para compartir sus experiencias, para trabajar en relaciones sociales que hagan hincapié en el cuidado y la preocupación por los demás, y donde se les inicie a formas de conocimiento que les den la convicción y la oportunidad de luchar por una calidad de vida de la que se beneficien todos los seres humanos (Giroux, 2006, p. 322).

21 Podemos mencionar el I Seminario Chileno sobre educación para la Paz y los Derechos Humanos (1984) del Consejo de Educación de Adultos de América Latina -CEAAL- y el II Curso Interdisciplinario en Derechos Humanos. 


\section{Conclusiones}

El objetivo de Identificar las discusiones y perspectivas sobre la formación integral permitió identificar tres perspectivas: la técnica, tecnológica y científica, la ética, humanística y espiritual; y, la democrática, histórica y socio-crítica. Criterios organizativos como ya fue planteado no son excluyentes y funcionan como modelos comprensivos, para reconocer que muchos de los documentos integran y se mueven entre las perspectivas. Lo interesante de este ejercicio de investigación documental y que aporta a un programa de posgrado en educación se puede resumir en cinco elementos sustantivos. El primero, está relacionado con la comprensión de la interceptación del campo de la formación integral por diferentes discursos que se yuxtaponen, en algunos casos se unen en otros se distancian; pero que esta dinámica responde a contextos históricos específicos que debemos interpretar. Latinoamérica es muestra fehaciente de cómo algunos énfasis y discursos están relacionados con el entramado histórico que se debe ahondar.

El segundo elemento lo dio la agrupación realizada, la cual permitió ver que todas las perspectivas plantean reflexiones que reconocen una serie de condiciones sociales, políticas y culturales similares dadas en la actualidad ante la cuales hay que estar pendiente. Las perspectivas realizan lecturas disimiles de lo que llamamos los huracanes socioeconómicos y político-culturales. La perspectiva técnica, tecnológica y científica enaltece los avances que propicia la competencia y el mercado como lógica hegemónica aunque existan textos que pidan deliberar el uso de la misma. Por el contrario, las otras perspectivas critican, llaman a la reflexión y al cambio de los primados que impone la perspectiva técnica, tecnológica o científica vista desde los principios capitalistas.

El tercer elemento permitió dar la razón en la presentación de estas perspectivas en la formación Integral del Programa. Las mismas permiten no solo ilustrar un posible ordenamiento en la pléyade de perspectivas, sino que permite formar a los maestrantes de manera investigativa, ya que la puesta en común demanda reconocer relaciones, tensiones y acuerdos entre perspectivas ${ }^{22}$. Es decir, ubica en perspectiva de acción de saber y para lograr esta acción del saber la investigación se muestra expedita; les propone un orden que debe ser tensionado, cuestionado,

22 Comprender la educación como un campo de tensiones viene de diferentes interpretaciones de desarrollos teóricos generados por las propuestas de Pierre Bourdieu y Michel Foucault. Ejemplos de su aplicación son posibles de ver en trabajos de (Ansaldi, 2012; Martínez Boom, 2004; Jiménez, 2011; 2014). 
modificado, complementado, etc. con nuevos documentos y textos que sigan ampliando la visión sobre la formación integral en nuestra región.

El cuarto elemento fue ver que hay múltiples comprensiones sobre lo pedagógico y los documentos se mueven entre ellas para generar propuestas de formación integral. Si tomáramos la distinción de pedagogía como arte, técnica, ciencia y/o saber, se nota que hay textos que exploran las diferentes posturas y las usan indistintamente; su criterio es la funcionalidad de la postura para indicar procesos formativos. Sería importante en otras investigaciones profundizar sobre las tendencias e implicaciones de estos usos. La médula frente a lo pedagógico fue comprender que cada perspectiva está relacionada con enfoques axiológicos que tienen implicaciones epistémicas y metodológicas en el proceso formativo. Podemos decir que todos los documentos invitan a los docentes a realizar procesos contextuales que sean auto-reflexivos en pos de revisar las prácticas pedagógicas que se realizan en la cotidianidad.

El quinto elemento sustantivo tiene que ver con que los procesos de formación integral que se realizan en el día a día, no es solamente la instrucción en contenidos y saberes que deben ser transmitidos aunque algunos documentos hagan énfasis en los mismos. La gran mayoría de textos le apuestan a la formación continua en la relación del maestro con sus estudiantes, discípulos o alumnos. Aquí debemos reconocer la ambivalencia que representa la educación a distancia, por un lado es una posibilidad, ya que facilita el acceso al proceso formativo y, por otro lado, cuando se deslinda de un acompañamiento queda en el paradigma técnico-masificante que olvida o aparta la formación en otras dimensiones humanas.

En las reflexiones generadas en los ámbitos formativos del programa de Maestría emergieron también tres elementos que tienen en común la apuesta por la formación integral. Aunque se reconoce que hay muchos más, los énfasis de los maestros en formación plantearon que esta educación debe apostarle a colaborar en: 1) resolución de conflictos de distintos órdenes mediante la formación holística para leer en múltiples dimensiones; 2) la lucha contra la pobreza; y 3) la apuesta por un desarrollo tecnológico, humano y social. Así las características de la Formación Integral en la Educación Superior de la Maestría en Educación demanda un énfasis investigativo y crítico que permita realizar lecturas novedosas y contextuales de cada uno de los paradigmas.

El poder de los pedagogos se hace evidente en el acto educativo en donde hay conocimiento e interés, y tal como Habermas lo mostró, hay que ser conscientes del poder ideológico que ha configurado el mundo. El enfoque positivista, pragmático y economicista que aún domina algunos lugares de la ciencia demanda que se repiense la relación de saber-poder. No se puede olvidar que la ciencia 
fue un saber en emergencia que pugnó contra hegemonías del medio evo que la denostaba, diría Foucault. Por ello, como maestros estamos en la obligación de hacer lecturas históricas que permitan reconocer las dificultades de posturas sectarias que olvidan el desarrollo de las múltiples dimensiones del ser humano. En el discurso de Doris Lessing para recibir el premio Príncipe de Asturias plantea que "la educación humanista, está desapareciendo. Cada vez más los gobiernos -entre ellos el británico- animan a los ciudadanos a adquirir conocimientos profesionales, mientras no se considera útil para la sociedad moderna la educación entendida como el desarrollo integral de la persona" (Lessing, 2001). Lo cual llama a ver que aunque en la época actual el sentido y los beneficios de este tipo de educación son puestos en duda, pues no responden a los estándares exigidos por la nueva sociedad globalizada, que busca garantizar la calidad y productividad de todos los procesos; los maestros deben establecer reflexiones y procesos didácticos para que la formación integral sea entendida como "un estilo educativo que pretende no sólo instruir a los estudiantes con los saberes específicos de las ciencias sino, también, ofrecerles los elementos necesarios para que crezcan como personas buscando desarrollar todas sus características, condiciones y potencialidades" (ACODESI, 2003, p. 6). No hay que olvidar reflexiones de economistas expuestas en el texto El precio de la desigualdad (Stiglitz, 2012) documento que reconoce que el modelo de producción e intercambio económico que ha dominado todos los demás órdenes de la vida ha generado un inmenso costo tanto económico como humano y somos nosotros los que no hemos querido hacer nada al respecto. Es parte de los procesos formativos el generar sentido de responsabilidad con entorno, social, político y ambiental; por ello las apuestas formativas de actores educativos comprometidos con la Democracia, la formación ciudadana y la consolidación de la Paz.

La maduración y el desarrollo personal son posibles mediante los ámbitos institucionales y disciplinares en donde los sujetos perfeccionen el dominio de ciertas habilidades básicas, como lo plantean las perspectivas de la formación integral. Pero "el sentido de la educación es ofrecer al educando algo más que contenidos teóricos, o el aprendizaje de técnicas; esto tiene que ser complementado con la adquisición de la visión global propia de la formación y con una actitud de compromiso con el mundo entorno, social [, ambiental, cultural] y político al que pertenece el educando" (Vargas, 2010, p. 154). Un maestro y un estudiante formados en este orden permitirían que lo extraño les hable y, si es parte de ellos, los transforme. 


\section{Referencias}

ACODESI. (2003). La Formación Integral y sus Dimensiones: Texto Didáctico. Bogotá: Editorial Kimpres Ltda. Recuperado de: http://www.ipatria.edu.mx/descargas/ LA_FORMACION_INTEGRAL_Y_SUS_DIMENSIONES_TEXTO_DIDACTICO.pdf.

Ansaldi, W. \& Giordano, V. (2012). América Latina: la construcción del orden: de las sociedades de masas a las sociedades en proceso de reestruturación [1aㅡ ed.]. Buenos Aires: Ariel.

Apple, M. (2001). Educar "como Dios manda". Mercados, niveles, religión y desigualdad. Madrid-España: Paidos.

Bambozzi, E, et al. (2013). ¿De qué hablamos cuando hablamos de Democracia Escolar? Córdoba: Del Copista.

Banco de la República, (2014). Desarrollo Integral. En: Biblioteca Virtual - Biblioteca Luís Ángel Arango. Recuperado de http://www.banrepcultural.org/node/64425

Bauman, Z. (2000). Modernidad líquida. Buenos Aires: Fondo de Cultura Económica.

Bauman, Z. (2013). Sobre la educación en un mundo líquido: conversaciones con Ricardo Mazzeo. España: Paidos Iberica.

. (2005). Vidas Desperdiciadas. La Modernidad y sus parias. Barcelona: Paidós.

Böhrm, W. (2005). Educar para ser persona. Córdoba: Universidad Católica de Córdoba.

Bolívar Botía, A. (2001). «Globalización e identidades: (Des)territorialización de la cultura». Revista de educación Número extraordinario (Número extraordinario). Recuperado de: http://redined.mecd.gob.es/xmlui/handle/11162/76560 , España: pp. 265-288.

Boustros-Ghali, B. (2003). La interacción entre democracia y desarrollo. Paris: Organización de las Naciones Unidas UNESCO. Recuperado de: http://unesdoc.unesco. org/images/0013/001323/132343s.pdf.

Chomsky, N. (2004). Los dilemas de la dominación. En: Chomsky, N. \& et al., Nueva Hegemonía Mundial /Comp. por Atilio A. Boron [pp. 15-35]. Buenos Aires: CLACSO.

Cifuentes, R. M. (2014). Diseños de proyectos de investigación cualitativa. Buenos Aires: Edicaciones Novedades Educativas.

Congreso de la República (1994). Ley 115 de Febrero 8 de 1994. Bogotá: Congreso de la República de Colombia.

Eriksen, T. H. (2001). Tyranny of the moment: Fast and slow time in the information age. London: Pluto Press.

Freire, P. (2007). Pedagogía de la Tolerancia. Buenos Aires: Fondo de Cultura Económica; Centro Regional para la Educación de Adultos en América Latina y el Caribe (CREAL).

Freire, P. (2005). Pedagogía del Oprimido[1970]. México: Siglo XXI. 
Giroux, H. (2006). La escuela y la lucha por la ciudadanía. México: Siglo XXI.

Gutmann, A. (2008). La identidad en democracia. Madrid: Katz Editores.

Hardt, M., \& Negri, A. (2002). Imperio. Buenos Aires: Paidos.

Hegel, G. W. (1985). Fenomenología del espíritu. España: Fondo de Cultura Económica, [1807].

Höffe, O. (2007). Ciudadano económico, ciudadano del Estado, ciudadano del mundo: ética política en la era de la globalización. Buenos Aires: Katz Editores.

Hoyos Vásquez, G. (1998). Ética para Ciudadanos. Bogotá: Instituto de Estudios Sociales y Culturales -PENSAR-; Universidad Javeriana. Recuperado de: www.oei.es/ valores2/eticahoyos.htm.

Jiménez, D. A. (2011). Afrocolombianidad y Educación: Genealogía de un discurso educativo. Pedagogía y Saberes. No. 34, [pp. 87-103]. Bogotá: Universidad Pedagógica Nacional.

Jiménez, D. A. (2014). Lo público, la ciudadanía y los valores: reflexiones, tensiones y posibilidades. En: Magistro, Vol. 8; No. 15 [pp. 179-200]. Bogotá: USTA.

León, H. \& Zemelman, H. (1997). Subjetivdad: humbrales del pensamiento social. Barcelona, México: Anthropos, Universidad Nacional Autónoma de México.

López, M.; Martínez, C. \& Useche, O. (2008). Ciudadanos en son de paz: propuestas de acción no violenta para Colombia. Bogotá: UNIMINUTO.

Martínez Boom, A. (2004). De la escuela expansiva a la escuela competitiva: dos modos de modernización en América Latina. Barcelona: Convenio Andrés Bello; Anthropos.

MEN. (s. f). La "formación integral" en el ámbito universitario colombiano (Marco de Reflexión). Ministerio de Educación Nacional. Recuperado de: http://www. mineducacion.gov.co/1621/articles-302596_archivo_pdf_medellin_formacionintegral_nueve.pdf

Nussbaum, M. (2010). Sin fines de lucro. Porqué la democracia necesita de las humanidades. Madrid: Katz Editores.

OEA. (2014). Desarrollo Integral. Organización de los Estados Americanos. Recuperado de: http://www.oas.org/es/temas/desarrollo_integral.asp

Picardo, O. (2004). Diccionario Enciclopédico de Ciencias de la Educación. El Salvador: C.A, Centro de Investigación Educativa, Colegio García Flamenco.

Ramos, D. (2004). La Formación Integral en la Aplicación Ética. Puerto Rico: Universidad Interamericana de Puerto Rico - Ponce.

Sacavino, S. (2012). Democracia y educación en Derechos Humanos en América Latina. Bogotá: Desde Abajo.

Santos, B. D. (1998). De la mano de Alicia: lo social y lo político en la posmodernidad. Bernal, C. (trad.) Bogotá: Siglo del Hombre Editores, Facultad de Derecho Universidad de los Andes, Ediciones Uniandes. 
Santos, B. d. (2009). Una epistemología del sur: la reinvención del conocimiento y la emancipación social. México: Siglo XXI; CLACSO.

Sen, A. (2006). Desarrollo y libertad. Bogotá: Planeta.

Stiglitz, J. (2012). El precio de la desigualdad. Buenos Aires: Aguilar, Altea, Taurus, Alfaguara.

Tedesco, J. C. (1995). El nuevo pacto educativo. Madrid: Anaya.

UNESCO. (2008). La educación de calidad, equidad y desarrollo sostenible: una concepción holística inspirada en las cuatro conferencias mundiales sobre la educación. Recuperado de: http://www.unesco.org/education/Synergies4conferences.pdf; New York: ONU.

Vargas Guillén, G. (2007). Efectos de formación y constitución de subjetividad. En Vargas Guillén, G. Formación y subjetividad [pp. 165-187]. Bogotá: Universidad Pedagógica Nacional.

Vargas, J. C. (2010). De La Formación Humanista A La Formación Integral: Reflexiones Sobre El Desplazamiento Del Sentido Y Fines De La Educación Superior. Praxis Filosófica , núm. 30, enero-junio, pp. 145-167,.

Vasco, C., Vasco, E., \& Ospina, H. (2009). Ética, política y ciudadanía. Bogotá: Siglo del Hombre Ediciones; Universidad de Manizales; y CINDE.

VUAD-USTA. (2014). La Formación Humanista en la Universidad Santo Tomás. Recuperado de: http://soda.ustadistancia.edu.co/enlinea/3momento_filosofiainstitucional_trinidadorozco/la_formacin_humanista_en_la_universidad_santo_toms. html

Wallerstein, I. (1996). Abrir las ciencias sociales. Madrid: Siglo XXI Editores. 